\title{
Academic Literacy for Deaf Postsecondary Students through Integrated Reading and Writing Instruction
}

\author{
Sue Livingston ${ }^{1}$ \\ ${ }^{1}$ Program for Deaf Adults/Education and Language Acquisition, LaGuardia Community College, The City \\ University of New York, USA \\ Correspondence: Sue Livingston, Program for Deaf Adults/Education and Language Acquisition, LaGuardia \\ Community College, The City University of New York, USA.
}

Received: April 4, 2021

Accepted: May 6, 2021

Online Published: May 10, 2021

doi: 10.5539/elt.v14n6p1

URL: https://doi.org/10.5539/elt.v14n6p1

\begin{abstract}
Based on theoretical findings from the literature on the integration of reading and writing pedagogies used with hearing postsecondary students to advance academic literacy, this article offers a model of instruction for achieving academic literacy in developmental and freshman composition courses composed of deaf students. Academic literacy is viewed as the product of acts of composing in reading and writing which best transpire through reciprocal rather than separate reading and writing activities. Pedagogical practices based on theoretical findings and teacher experience are presented as a model of instruction, exemplified as artifacts in online supplementary materials and juxtaposed with practices used with hearing students. Differences between the practices are seen in accommodations for students who learn visually, the amount of guidance provided and more opportunities for extensive practice.
\end{abstract}

Keywords: integrated reading and writing, deaf students, writing, academic literacy, developmental reading and writing, reading

\section{Introduction}

While there are increasing numbers of deaf students attending college in the United States, many, if not most, continue to read below the level of their hearing peers and below what is expected for post-secondary academic outcomes (Marschark \& Rosica, 2021). Research studies of the writing abilities of deaf students also reveal writing skills that do not match similarly-aged hearing peers (Mayer \& Trezek, 2019). And while evidence-based practices exist to assist deaf students with their reading and writing (Berent, 1993; Palmberg \& Rask, 2016; Wolbers et al., 2015), these practices have primarily focused on either younger deaf students or have targeted each domain separately. This article proposes that in order for postsecondary deaf students to improve their academic literacy they will need to approach reading and writing as integrated rather than separated tasks. Theory and practice from the literature on composition research with postsecondary hearing and second-language students will be used to propose a model of integrated reading and writing instruction for deaf postsecondary students in either developmental or freshman composition courses. A corresponding body of literature of integrated theory and practice for the teaching of reading and writing does not exist in the field of deaf education.

\subsection{Academic Literacy and Integrated Reading and Writing Instruction}

Academic literacy is viewed as ways in which college students work through, analyze and interpret texts in order to produce written intellectual work based on these texts. In the context of developmental and first-year composition courses, the intellectual work is primarily the writing of essays for which students must recognize that writing is a form of thinking in which arguments are sustained and ideas are synthesized, and that these arguments and ideas stem from what they read and the experiences they bring to the reading (Intersegmental). From texts assigned, students establish the significance of a controlling idea or create an idea sparked by the text that others have not thought about in an effort to have a take-away of their own. Students are asked "to do something with their knowledge, not merely to remember it" (Voge, 2007), and, in so doing, recruit both their reading and writing abilities in an effort to think harder about the points they are making. Typically, students are asked to talk back to something read, to propose a solution to a problem, to shed new light on an issue or to correct a misunderstanding (Bean, 1996). 
This view of academic literacy contrasts with historical perspectives that have argued for a separation of the teaching of reading and writing. Morrow (1997) has reported that the teaching of reading has been viewed with diminished importance in the teaching of writing. She writes that in academic writing courses "practicing invention strategies, improving flawed paragraphs or revising sample sentences" (457) have been given precedence and that assigning too much reading has been viewed as being counterproductive as teachers might spend students' time discussing the readings instead of doing the real work of composing. Clifford (as cited in Fitzgerald \& Shanahan, 2000) speculates about a professional division between reading and writing educators who have "developed separate curricula, instructional materials, and assessments" (2) as prescribed by different professional organizations. These differences in pedagogy and assessment measures might be a function of the way teachers are trained. Using San Francisco State University as an example, Goen and Gillotte-Tropp (2003) claim that reading and writing instructors receive graduate training in either college composition or reading with few opportunities for them to see how these literacies are linked.

Of particular concern to Sullivan, Tinberg, and Blau (2017) is the very reductive and outdated view of reading that transpires when reading and writing are separated and when reading abilities are assessed by standardized tests or specified as part of state standards. In these situations, readers are viewed as passive recipients of information making it difficult for them to use information gleaned from reading in any authentic academic way. Instead of using reading to transact with text, students are asked to transmit their understanding of a text through "answer-getting dispositions" where students seek "right answers quickly" (Wardle as cited in Sullivan et al., 2017). Typically, as documented in college reading textbooks, students answer questions about literal versus inferential information in passages, about the main idea in out-of-context passages and about vocabulary that is not domain-specific (Holschuh \& Paulson, 2013). If questions are answered correctly, reading skill has been captured and attained, and students can be considered college-level reading proficient.

Jolliffe (2017), however, contends that reading abilities are not captured and considered complete but rather that "students' acquisition of college-level reading abilities exists on a continuum" (p. 4) wherein students reading becomes stronger as they move through their years in school. Nowacek and James (as cited in Sullivan et al., 2017) maintain that expert college-level reading happens when students' contextual knowledge is activated for a particular reading rather than when there is metacognitive awareness of different reading strategies that supposedly transfer to different texts. Students need "highly-elaborated mental maps" in order to engage with a reading ( $\mathrm{p}$. 301). Such maps refer to students' spheres of existing knowledge (Adams, 2010-2011) and reflect concepts that are symbolized as vocabulary and phrases. To understand new vocabulary and phrases requires students to have some pre-requisite specific knowledge about what they are reading rather than knowing how to recruit metacognitive skills that supposedly can be employed for any text.

Similarly with respect to writing, according to Rodby and Fox (2000), students' writing abilities should not be thought of as "a static bunch of skills to be moved from place to place" (p. 89). Instead, writing is an array of practices that assist writers in conveying their particular meaning and that vary depending on what and how knowledge and experience are being used. The authors use the example of the activity of revision and explain that because revising is not a discrete skill, students will not know how to revise in all situations with all texts.

It would appear then that achieving academic literacy would require viewing reading and writing not as skills with absolute values but as thinking practices that change from one academic task to another and that evolve over time. Research over the past years has shown that these practices foster a strong reciprocal relationship between reading and writing (Bartholomae \& Petrosky, 1986; Fitzgerald \& Shanahan, 2000; Rosenblatt, 2013) and that teaching reading and writing as separate skills loses this relational value and becomes less effective for student learning (McCormick, 1994; Shanahan \& Lomax, 1988).

\subsection{Reading and Writing as Acts of Composing}

Hirvela (2004) maintains that reading and writing are best drawn together through acts of composing where they are used to make meaning by utilizing the constructive process writers use when creating text. This happens by "establishing links to supplies of input, such as source texts, and negotiating new or extended meanings for that input in relationship to other ideas or input in the text being written" (p. 182). Hirvela's point is that we start to understand a text better once we have revisited or rearranged it by writing about it or by placing that text in the context of other texts. We compose a work of writing by integrating the knowledge created from one's interpretation of the texts with the use of elements of the writing process itself. According to Nelson (as cited in Hirvela), "reading and writing processes tend to blur and a person is in two roles concurrently--a reader building meaning from a text and a writer building meaning for a text" (p. 20). Reading and writing, therefore, are now commonly accepted as parallel processes (Armstrong, Williams, \& Stahl, 2018). 
Readers composing meaning from a text depend on writing. Often referred to as "writing to read," writing before, during or after reading "allows one to discover and consider one's stance, one's interpretation, one's immediate reactions to a text" (Zamel, 1992, p. 470). Zamel explains that when readers underline portions of text, scribble comments in the margins, and verbalize reactions, they are composing interpretations that become "overt, concrete and tangible" (p. 470) which makes reading more focused and effective. McPhee (2017) discusses the usefulness of studying reading notes, separating them into categories and coding them in order to think more deeply about ideas for writing. These processes require multiple re-reads of text and notes making reading a recursive process in pursuit of understanding and invention. Blanton (1993) claims that "we don't know what we've read until we begin to work with it by talking and writing about it" (p. 241). Understanding reading then comes with multiple attempts at active engagement with a specific text.

Readers composing meaning for their own text first depend on reading good models of writing to emulate. In the college setting, often this writing is written by other students as students find such reading enjoyable, accessible and instructive as it "reveals mastery of written structures ... access to ideas [and awareness] of how genres and patterns shape ideas" (Morrow, 1997, p. 454). They begin to see how to use readings--how to synthesize several sources--by studying significant amounts of student writing (p. 458). Thereafter, creating an academic essay that will synthesize ideas from their own sources for a purpose of their own will require more focused reading and re-reading. This becomes especially apparent when students write summaries of ideas read and when they incorporate quotations from readings (Campbell, 1990). In these instances, summaries and quotations must be used correctly in support of students' own guiding ideas. Therefore Blau (as cited in Sullivan et al., 2017) maintains that the quality of students' writing depends on the quality of their reading of their sources. He contends that it is through the process of revision which requires "recursive, layered, and self-correcting discovery and refinement of the writer's own meaning" (pp. 275-276) that students will enhance their reading and understanding of their sources. As students revise their work, they begin to read more precisely, gain more insights and discover what it is they want to say.

\subsection{Pedagogical Principles}

While interest in integrating reading and writing pedagogies has increased recently due to statewide and institutional mandates to accelerate students through developmental education (Holschuh \& Paulson, 2013; Xu, 2016), some colleges have been using integration pedagogies for years (Bartholomae \& Petrosky, 1986; Fitzgerald, 2003; Goen \& Gillotte-Tropp, 2003). Fitzgerald (2003) reports the results of a six-month project undertaken by English faculty at Chabot College to research basic writing and reading pedagogy which resulted in a statement of philosophic principles for all English courses called the Throughline which is summarized here:

- Integrate reading, writing, critical thinking, speaking, and listening;

- Address directly students' reading practices to include reading of more breadth and depth;

- Require writing of varying length and complexity not as a progression from sentence to paragraph to essay;

- Emphasize critical thinking: drawing inferences, synthesizing, arguing, asking questions, sensing, feeling and imagining;

- Create settings that explicitly and directly forge links to reading and writing including small- and large-group discussions, student-teacher conferences, notetaking and feedback;

- Include full-length works that integrate thematically, either fiction or non-fiction, that incur both personal and analytical responses.

More currently, the California Acceleration Project (CAP), an organization that supports faculty in California's community colleges offering integrated reading and writing courses, has developed pedagogic principles grounded in the accumulated 40-year experience of community college teachers who advocate for backward design and collaborative, low-stakes practice (Hern, 2013). Hern explains that a backward designed developmental course should "look and feel like a good, standard college English course, only with more support and guidance" (p. 7). Such support is seen in collaborative, low-stakes in-class assignments that give students practice with the skills and content needed for a particular assignment before that assignment is graded. CAP hosts a website which lists the thematic content for a variety of integrated reading and writing courses along with suggested texts that are related and that cross disciplinary boundaries (Hern \& Serpas, 2016).

In a study that drew on interview data with 161 instructors and administrators, Bickerstaff and Raufman (2017) report the challenges faced by teachers transitioning from teaching stand-alone reading and writing courses to teaching newly integrated reading and writing courses. Integration for one group of teachers was "additive" in that 
assignments from previous stand-alone courses remained the same but were combined. Activities and materials were exchanged between reading and writing teachers and learning focused on the mastery of specific skills. There was no clear framework for an integrated course. Courses that were fully integrated featured text-based writing and embedded skills and strategy instruction where, as an example, students were explicitly taught quote integration for each required assignment. Teachers teaching in the fully integrated course reported more satisfaction than those teaching using additive pedagogies who felt that there was not enough time to cover all content and activities from the previous stand-alone courses.

Although empirical research on the outcomes of integrated reading and writing instruction is limited, there are indications that integrated instruction in either accelerated or regular course frameworks is benefitting students. Hern (2011) reports that integrated reading and writing classes at Chabot College one level below college English "can bring significant, long-term, large-scale gains in student completion of college English" (p. 4). Edgecombe et al. (2014) contend that a developmental English curriculum that is "seamlessly aligned" with college-level English fosters critical academic literacy skills that students use for the long term. Lockhart and Soliday (2016) interviewed students who said that learning how to integrate their reading assignments with their writing assignments in an English course helped them in their content courses with more challenging readings. They emphasized that it was their newly-learned "reading practices which allowed them to enter the discourse of their major" (p. 24).

According to Armstrong et al. (2018), the most important conversation happening today at the college level is about how to integrate the teaching of reading and writing in order to advance academic literacy. They write that knowledge of the why-the theoretical research that explains the reading-writing connection--and the how--the pedagogy that puts that theory into practice--is needed.

\section{Method}

Having discussed the meaning of academic literacy, the conceptual links between reading and writing and the instructional principles used in several integrated reading and writing courses for hearing students, this paper offers a model of integrated reading and writing instruction for deaf students in either developmental or first-year composition courses based on the research findings discussed above as well as over 35 years of experience in teaching reading and writing to deaf postsecondary students at a community college in the northeastern United States with 10 of those years devoted to using integrative strategies in developmental writing and freshman composition courses. The model will present the sequence of the interplay of theory and practice in integrating reading and writing tasks for a typical essay assignment for a freshman composition course for deaf students. Instructional artifacts referred to can be found in the Supplementary Materials section online at https://bit.ly/3tjK3X4

\section{The Model: Using the Reading-Writing Connection to Enhance Academic Literacy Instruction for Deaf Postsecondary Students}

\subsection{Assignment Content and Expected Outcomes}

\subsubsection{The Theory}

Shannon (1997) believes that the integration of reading and writing should not be an end in itself but a vehicle for accomplishing learning goals which works best when there are clear outcomes set for which instructors can plan, teach and assess.

\subsubsection{The Practice}

Typically in freshman composition courses, the readings are expository (non-fiction). In this course, deaf students are assigned authentic readings of current and controversial news events that are both of high interest and readable to discuss and think about for a pre-determined essay assignment (see Artifacts 1 and 2). Assignments stem from events happening or that happened to people to whom students can relate, and additional readings are offered to provide context and alternative perspectives. Initial readings pull students in to a person's or persons' predicaments which fosters engagement and thereby more effortful reading. As the readings progress, and more and more context becomes established, reading becomes easier. Of importance is the number of readings offered as the more students read and discuss the readings, the more they will have ideas to write about. Essay topics are written in ways that lead students to establish their own takeaway from the assigned readings and specify the outcomes expected for the assignment which reflect how essays will be assessed. 


\subsection{Reading as an Act of Composing}

\subsubsection{Preparation for Reading}

\subsubsection{The Theory}

Nowacek and James (as cited in Sullivan et al., 2017) maintain that expert college-level reading happens when students' contextual knowledge is activated for a particular reading. Students need "highly-elaborated mental maps" in order to engage with a reading (p. 301).

\subsubsection{The Practice}

Students need to be prepared for a reading or a group of readings. Prior to assigning readings, they are checked for ideas that are most likely out of the present realm of student understanding. Through a combination of Google Images, YouTube videos or well-pictured, authentic internet websites (see Artifact 3), students become engaged with concepts that are made understandable because they are visual. As the visualizations are discussed, the phrases needed to read and write about them are written for all to see. In this way, heretofore unfamiliar ideas that students will meet in text are made more familiar by being visualized and more readable by being interpreted into written phrases. These practices will assist students in creating a more fluent reading experience.

\subsection{Annotation and Text Integration}

\subsubsection{The Theory}

Zamel (1992) explains that when readers underline portions of text, scribble comments in the margins, and verbalize reactions, they are composing interpretations that become "overt, concrete and tangible" (p. 470) which makes reading more focused and effective. Horning (2017) maintains that "college-level academic reading is a complex, recursive process in which readers actively and critically understand and create meaning through connections with text" (p. 7).

\subsubsection{The Practice: Annotation}

Students benefit from guidance in making meaning from text. This guidance is best offered through assignments that assist students in understanding the scaffolding of texts, enabling them to see how authors of exposition set up general and specific ideas--what they will need to do as essay writers. This can be accomplished by annotating the text with students (Artifact 4). Here, students are asked to read one or two paragraphs and then to discuss the "umbrella idea" or major point of the paragraph(s) which gets written or, at times, graphically presented in the right-hand margin. This is where complicated ideas are re-phrased into understandable language or clearly depicted through rough stick figure or simple diagrams culled from discussion of the selected paragraph(s). This is also where students practice summarizing points which they will need to do when they write their essay. Students are then brought back into the text to underline the more specific language that exemplifies or explains the right-hand margin major point. With a better understanding of the text, the left-hand margin becomes the place for students to transact or connect with it: to write down their comments about the paragraph(s) and to make these unique responses known to their classmates through continued discussion and, at times, mock television interviews or debates. Here is where teaching slows down allowing students opportunities to see the ideas of their peers and the chance for them to offer additional perspectives that might spur additional thinking. It is where discussion of ideas begins to lift the quality of thought, making it more academic in nature. It is important for students to learn to work their text through summarizing, underlining and commenting on it to make it understandable so that they can subsequently go back to it to read it fluently and to find correctly understood ideas that they will address in their essays.

\subsubsection{The Practice: Text Integration}

Horning's (2017) use of the word "recursive" as it applies to college-level reading is best understood to mean that a reading needs to be attempted more than just once. We think of writing as a recursive process wherein as drafts are revised, ideas become elucidated; rarely do we also think about reading as a recursive process. But only when we take the time to work a text more than once does its meaning become clearer. In the developmental or freshman composition classroom, reading and writing can be drawn closer together by creating opportunities for students to revisit their reading by requiring them to integrate quotes from it that support or extend the points they are making and by understanding a quote well enough to comment about it appropriately and to explain how it fits into the point they are making (see Artifact 5). This is pulling reading and writing together in authentic ways as students work to see the logic of their new thinking and, as explained below in section 3.5, often requires re-reading. 


\subsection{Writing as an Act of Composing}

\subsubsection{Model Student Essay}

\subsubsection{The Theory}

Morrow (1997) contends that students begin to see how to shape their own ideas and how to use their readings by studying significant amounts of student writing.

\subsubsection{The Practice}

Before students can write essays, they must be able to understand how they are constructed. In order to do this, they must slowly read and take notes on models of what it is they will be expected to do. Former-students' essays about topics of interest that have been revised and edited offer students ways of understanding the various rhetorical roles paragraphs play, the cohesive devices that tie paragraphs together and how and why parts of readings are recruited through summarizing, quoting and commenting on the quotes to help support a point being made. Artifact 6 illustrates the slow-reading analysis and annotation of a model student essay.

\subsection{Preliminary Thinking: Essay Outline}

\subsubsection{The Theory}

In their description of an integrated reading and writing course, Bartholomae and Petrosky (1986) say that students "must shuttle between ... their understanding of what they have read and their understanding of what they must say to us about what they have read" (p. 4). Hirvela (2004) explains that in synthesizing tasks when reading is integrated with essay writing, as an example, students must quote and paraphrase according to some guiding principle or idea which according to Campbell (1990) requires "reading, understanding, learning, relating, planning, writing, revising ... and orchestrating" (p. 211).

\subsubsection{The Practice}

Students start with an idea of what they want to say in response to an essay topic and then use text(s) to further enhance this idea. They can become derailed in their attempts to stay with their guiding point and to integrate corroborating text at the same time. This becomes apparent when their points and supporting quotes do not work together--either their quote does not support their point or their comment about a quote does not reflect the intent of the quote. In addition, at times, students include references to text that are misinterpreted in their attempt to summarize them. These meaning mismatches are typically the result of not fully understanding their reading. An in-depth discussion about the meaning of the portion of text being referred to would need to take place, further underscoring the recursive nature of the reading process and how thoughts about reading must be based on accurate readings and correctly intertwined with writing.

Discussions with students about text integration start early in the essay-writing process where ideas are still percolating and growing. Here is where the interplay of language and logic take center stage as students are asked to re-think ideas by re-reading, discussing and re-writing initial ones. Students are therefore required to share outlines (see Artifact 7) of their preliminary thinking about an essay topic which must include references to portions of text they will be using. These outlines are projected for class members to see and respond to. Attention is paid to how students work with their texts and scaffold their ideas within essay body paragraphs based on the essay topic they were assigned. This "just-in-time instruction" at the outline stage offers students the chance to produce smoother flowing first drafts.

\subsection{Explicit Response to Academic Writing}

\subsubsection{The Theory}

Blau (as cited in Sullivan et al., 2017) contends that it is through the process of revision which requires "recursive, layered, and self-correcting discovery and refinement of the writer's own meaning" (pp. 275-276) that students will enhance their reading and understanding of their sources. Zamel and Spack (2006) maintain that for L2 learners, learning English is intimately dependent upon being engaged with tasks of literacy in subject-area courses. They state that students make progress with language when struggling to understand course material because in that struggle, they develop new strategies for learning both the subject matter and for acquiring the language of that subject matter.

\subsubsection{The Practice}

As students draw closer and closer to a finished essay, as they re-write drafts, both their knowledge of the subject matter as presented in their texts and their expression of that knowledge in academic written English become stronger. As students read their essays more closely, they refine their points to make them both clearer and more 
accurate. With substantial assistance, they learn to check that enough logical commentary and elaboration have been provided, that information is not repeated, that unimportant information is deleted, that examples are true examples of what is being exemplified, that the order and presentation of ideas are smooth rather than bumpy and that points have been tied up. In one-on-one conferences with a teacher, students come to understand what it is they want to say as they re-read portions of texts and are explicitly shown where and how to revise for a next draft. Called explicit response to academic writing or feedback (see Artifact 8), the end product is a revised subsequent draft that is tighter and more important to read--an example of a work product that reflects academic literacy because students have come to a deeper understanding of a subject through the in-tandem nature of the reading and writing tasks required throughout the revision process.

\section{Why the Model Suits the Needs of Deaf Postsecondary Students}

Adapting the work of Hern (2013) with input from English and ESL faculty at Irvine Valley College and Solano College, Serpas (2019) created an instructional cycle for hearing postsecondary students taking integrated reading and writing courses as part of the California Acceleration Project mentioned above. If Serpas's instructional cycle is compared with the model presented in this article, similarities and differences become apparent.

Table 1. A comparison of Serpas's (2019) instructional cycle for integrated reading and writing assignments for postsecondary hearing students with a model of instruction for postsecondary deaf students

\begin{tabular}{lll}
\hline Instructional component & Serpas's instructional cycle & A model of instruction for deaf students \\
\hline Content of Instruction & Thematic readings for essay writing & Thematic readings for essay writing \\
Expected Outcomes & $\begin{array}{l}\text { Essays evaluated against an assignment } \\
\text { rubric }\end{array}$ & $\begin{array}{l}\text { Essays evaluated against an assignment rubric. } \\
\text { Suggestions on how to fulfill evaluation criteria } \\
\text { are embedded in the essay topic. }\end{array}$ \\
\hline
\end{tabular}

Reading as an Act of

Composing

Preparation for reading Discussion and activities activate

Unfamiliar terms/concepts in readings are background knowledge; guidance for key presented visually, discussed and labeled. terms and cultural references

Acts of composing At home: summary writing, double-entry journals and text annotation

In class: guided scaffolding of general to specific ideas in text through annotation, summarizing, underlining and using pictorial representations. Transactions with text recorded on text

In class: structured group discussions, debates, games, poster presentations

In class: structured group discussions, debates, mock interviews

In-class practice with quoting, In-class practice with quoting within essay summarizing, relating texts to students' outlines where quotes must accurately enhance own ideas the points students are making within each essay body

Writing as an Act of

Composing

Models of writing

Response to writing
After students submit their essays, student work that comes closest to assignment objectives are examined for strengths.

There are peer reviews and sometimes one-on-one conferences to discuss preliminary drafts.

Students whose work does not meet assignment objectives meet with the instructor to discuss revision plans.
Before students write their essays, they study models of student essays for rhetorical roles of paragraphs, cohesive devices and techniques for text integration.

Students share outlines of their essays with peers and teacher.

All students re-write drafts after receiving explicit response from the teacher in one-on-one conferences; explicit response continues throughout the drafting process.

Table 1 shows that both models offer continuous integration of reading and writing tasks through a process-based approach that builds and recycles as it is recruited to assist students in completing an academic essay. Support and scaffolding are built into each model and students are active participants in their learning with opportunities to 
discuss and use ideas garnered through assigned readings. According to Armstrong et al. (2018), these principles serve as the backbone for most integrated reading and writing programs across the United States, but what they claim might differ would be the type of scaffolding and level of support needed "based on where students are in their academic literacy development" (p. 154). The components of integrated reading and writing instruction for postsecondary deaf learners are evident in Serpas's instructional model but differ with respect to the need to accommodate students who learn visually, the amount of guidance provided and opportunities for extensive practice. As examples, unfamiliar concepts in readings are made clearer through visual means, capitalizing on the power of pictures and video to enhance understanding while obviating the need to explain unfamiliar ideas through unfamiliar language. In addition, short summaries of text paragraphs and responses to them are made visual through projected text annotation that shows big paragraph ideas and smaller paragraph details in relation to one another. The language needed for transactions with texts is likewise projected enabling students to read the commentary and thereby learn the spelling of possibly needed words.

Additional guidance and practice opportunities are noted between the models as well. For deaf students, most reading work is done in class and guided where complex language in text is either made visual or, in the absence of appropriate pictures or videos, re-phrased into more understandable language. While both models use rubrics for evaluation purposes, for deaf students, expected outcomes are written into essay topic directions which scaffolds the expected structure for a particular assignment at the outset of composing. Models of effective student work are studied before writing begins as opposed to after it is completed, and outlines for essays are required serving to ensure that text integration is appropriate before essay writing begins. Most initial feedback is between student and teacher and is directive in nature so that students clearly understand how revision needs to proceed. Re-reading of source texts transpires throughout the revision process--over two or three drafts--so that text integration is appropriate, reflecting the recursive nature of college-level reading and the symbiotic relation between reading and writing.

\section{Discussion and Conclusion}

The essence of the model of integrated reading and writing instruction presented in this article speaks to the need for deaf students to become more knowledgeable about the topics they are assigned by becoming better readers and writers about them. It is the reading and writing that drive the learning and, reciprocally, in the process of learning, reading and writing abilities are advanced. The model presented here for developmental or freshman composition courses reflects similar methods seen in discipline-specific courses that require students to gather and analyze evidence and produce a written interpretation of the evidence. Monte-Sano (2011) examined the discipline-specific literacy instruction of a history teacher teaching about the Civil War and noted the simultaneous growth in students' historical reasoning and writing were attributed to instructional strategies such as annotating primary source readings, using writing prompts that required synthesis of issues and receiving feedback that focused on use and accuracy of source interpretations. These kinds of academic literacy activities go hand in hand with academic learning and are far different from requiring students to write full-length summaries of texts or to answer end-of-chapter comprehension questions just to check understanding of a text rather than to do something with a text or texts to create richer fields of understanding.

It is well known that effective reading leads to effective writing. In the model presented here, reading is as recursive a process as the writing process itself. It doesn't happen once but multiple times throughout the work on an essay and is approached in a variety of ways right up until final drafts where what was read is incorporated into a new take on an issue. Each time a reading is used, its vocabulary and language phrases are more likely to be recruited for future use, as practice with using them will assist students in remembering them. The more students remember, the more complex their mental maps will become making students stronger readers and writers for more advanced assignments.

The model presented here reflects elements of backward design mentioned in section 1.3 which considers literacy practices students will need to do in subsequent courses and then supports development of them in lower-level courses. While some might question the abilities of deaf developmental readers and writers to benefit from the integrated tasks presented here, all students in academic disciplines will need to write about what they read and should be prepared to do so. With this in mind, the model could be tweaked and practiced as early as possible. Differences for less-prepared readers and writers would be seen in the level of texts selected, the number of texts required per assignment and perhaps in the number of assignments.

If deaf students are in mainstream settings, differences between this model for a class of all deaf students and Serpas's model for hearing students are certainly not insurmountable. Hearing students, and especially hearing language learners, would certainly benefit from pictorial displays of words and concepts and new language and 
phrases that are written for all to see. In addition, continuing support with reading integration, organizational support for essay creation and explicit response to drafts would comprise an inclusive instructional design beneficial to all.

Perhaps most crucial in the pursuit of academic literacy for deaf postsecondary students is a rethinking of how language and literacy are situated within educational settings. The move away from teaching developmental reading and writing as separate skills will necessitate a reorientation in thinking that reading and writing are distinct skills in need of mastery prior to doing academic coursework to the view that they perhaps work best together in fulfilling challenging academic assignments. Rather than thinking of improving literacy skills, conversations need to be had about working backwards from what content it is that we want students to learn and how to get there through the synergy produced by viewing reading and writing as composing activities. If a solid curriculum is built around compelling academic assignments, reading and writing abilities will coalesce if teachers are prepared to use them to enhance student knowledge. Assisting teachers in obtaining this preparation would be a logical next step.

\section{References}

Adams, M. J. (2010-2011). Advancing our students' language and literacy: The challenge of complex texts. American Educator, 34(4), 4-12.

Armstrong, S. L., Williams, J. L., \& Stahl, N. A. (2018). Reading and writing. In R. F. Flippo \& T. W. Bean (Eds.), Handbook of college reading and study strategy research (pp. 143-167). Routledge. https://doi.org/10.4324/9781315629810-11

Bartholomae, D., \& Petrosky, A. (1986). Facts, artifacts, and counter facts: Theory and method for a reading and writing course. Boynton/Cook.

Bean, J. C. (1996). Engaging ideas: The professor's guide to integrating writing, critical Thinking, and active learning in the classroom. Jossey-Bass Inc.

Berent, G. P. (1993). Improvements in the English syntax of deaf college students. American Annals of the Deaf, 138(1), 55-61. https://doi.org/10.1353/aad.2012.0591

Bickerstaff, S., \& Raufman, J. (2017). From “additive” to "integrative”: Experiences of faculty teaching developmental integrative reading and writing courses (Research Report No. 96). Columbia University, Teachers College, Community College Research Center. Retrieved from https://ccrc.tc.columbia.edu/media/k2/attachments/faculty-experiences-teaching-evelopmental-reading-writi ng.pdf

Blanton, L. L. (1993). Reading as performance: Reframing the function of reading. In J.G. Carson \& I. Leki (Eds.), Reading in the composition classroom: Second language perspectives (pp. 234-242). Heinle \& Heinle.

Campell, C. (1990). Writing in others' words: Using background reading text in academic compositions. In B. Kroll (Ed.), Second language writing: Research insights for the classroom (pp. 211-230). Cambridge University Press. https://doi.org/10.1017/CBO9781139524551.018

Edgecomb, N., Jaggars, S. S., Xu, D., \& Barragan, M. (2014). Accelerating the integrated instruction of developmental reading and writing at Chabot College. Columbia University, Teachers College, Community College Research Center. Retrieved from https://ccrc.tc.columbia.edu/media/k2/attachments/accelerating-integrated-developmental-reading-and-writi ng-at-chabot.pdf

Fitzgerald, J., \& Shanahan, T. (2000). Reading and writing relations and their development. Educational Psychologist, 35(1), 39-50. https://doi.org/10.1207/S15326985EP3501_5

Fitzgerald, S. H. (2003). Serving basic writers: One community college's mission statements. Journal of Basic Writing, 22(1), 5-12. https://doi.org/10.37514/JBW-J.2003.22.1.03

Goen, S., \& Gillotte-Tropp, H. (2003). Integrating reading and writing: A response to the basic writing "crisis." Journal of Basic Writing, 22, 90-113. https://doi.org/10.37514/JBW-J.2003.22.2.06

Hern, K. (2012). Acceleration Across California: Shorter Pathways in Developmental English and Math. Change: The Magazine of Higher Learning, 44(3), 60-68. https://doi.org/10.1080/00091383.2012.672917 
Hern, K. (2011). Accelerated English at Chabot College: A synthesis of key findings. Hayward, CA: California Acceleration Project. Retrieved

from https://cap.3csn.org/files/2012/02/Chabot-Accelerated-English-Synthesis1.pdf

Hern, K., \& Snell, M. (2013). Toward a vision of accelerated curriculum and pedagogy: High challenge, high support classrooms for underprepared students. Learning Works. Retrieved from https://www.learningworksca.org/accelerated-pedagogy/

Hern, K., \& Serpas, S. (Eds.) (2016). Thematic approaches for integrating reading and writing. California Acceleration Project. Retrieved from https://accelerationproject.org/Publications/ctl/ArticleView/mid/654/articleId/34/Thematic-Approaches-forIntegrated-Reading-and-Writing

Hirvela, A. (2004). Connecting reading \& writing in second language writing instruction. The University of Michigan Press. https://doi.org/10.3998/mpub.23736

Holschuh, J. P., \& Paulson, E. J. (2013). The terrain of college developmental reading. The College Reading Association. Retrieved from https://www.crla.net/images/whitepaper/TheTerrainofCollege91913.pdf

Horning, A. S., Gollnitz, D. L. \& Haller, C. R. (2017). What is college-level reading? University Press of Colorado. https://doi.org/10.37514/ATD-B.2017.0001

Intersegmental Committee of the Academic Senates. (2002). Academic literacy: A statement of competencies expected of students entering California's public colleges and universities. Retrieved from https://senate.universityofcalifornia.edu/_files/reports/acadlit.pdf

Jolliffe, D. A. (2017). Learning to read as continuing education revisited: An active decade, but much remains to be done. In P. Sullivan, H. Tinberg \& S. Blau (Eds.), Deep reading: Teaching reading in the writing classroom (pp. 3-22). National Council of Teachers of English.

Lockhart, T., \& Soliday, M. (2016). The critical place of reading in writing transfer (and beyond): A report of student experiences. Pedagogy, 16(1), 23-37. https://doi.org/10.1215/15314200-3158589

Marschark, M., \& Rosica, M. (2021). Reading abilities of deaf college students. In S. Easterbrooks \& H. Dostal (Eds.), The Oxford handbook of deaf studies in literacy (pp. 323-337). Oxford University Press. https://doi.org/10.1093/oxfordhb/9780197508268.013.23

McCormick, K. (1994). The culture of reading \& the teaching of English. Manchester University Press.

McPhee, J. (2017). Draft No. 4: On the writing process. Farrar, Straus and Giroux.

Monte-Sano, C. (2011). Beyond reading comprehension and summary: Learning to read and write in history by focusing on evidence, perspective, and interpretation. Curriculum Inquiry, 41(2), 212-249. https://doi.org/10.1111/j.1467-873X.2011.00547.x

Morrow, N. (1997). The role of reading in the composition classroom. Journal of Advanced Composition, 17, $453-472$.

Palmberg, G., \& Rask. (2016). A comprehensive reading intervention: Positive postsecondary outcomes and a promising practice for students who are deaf or hard of hearing. In M. Marschark, V. Lampropoulou, \& E. Skordilis (Eds.), Diversity in deaf education (pp. 417-439). Oxford University Press. https://doi.org/10.1093/acprof:oso/9780190493073.003.0015

Rodby, J., \& Fox, T. (2000). Basic work and material acts: The ironies, discrepancies, and disjunctures of basic $\begin{array}{lllll}\text { writing and mainstreaming. Journal of Basic Writing, 19, 84. } & \text {. }\end{array}$ https://doi.org/10.37514/JBW-J.2000.19.1.09

Rosenblatt, L. M. (2013). The transactional model of reading and writing. In D. E. Alvermann, N. J. Unrau, \& R. B. Ruddell (Eds.), Theoretical models and processes of reading (6th ed., pp. 923-956). International Reading Association. https://doi.org/10.1598/0710.35

Serpas, S. (2019, June). High challenge, high support pedagogy for English composition. Paper presented at the Conference on Acceleration in Developmental Education, San Diego, CA. Retrieved from https://alp-deved.org/2019/06/high-challenge-high-support-pedagogy-for-english-composition/\#more-5453

Shanahan, T. (1997). Reading-writing relationships, thematic units, inquiry learning . . . in pursuit of effective integrated literacy instruction. The Reading Teacher, 51(1), 12-19. 
Shanahan, T., \& Lomax, R. (1988). A developmental comparison of three theoretical models of the reading-writing relationship. Research in the Teaching of English, 22(2), 196-212.

Spencer, P. E., \& Marschark, M. (2010). Evidence-based practice in educating deaf and hard-of-hearing students. Oxford University Press.

Sullivan, P., Tinberg, H., \& Blau, S. (2017). Deep reading: Teaching reading in the writing classroom. National Council of Teachers of English.

Voge, D. (2007). Strategic learning requires starting with the end in mind, but what is the appropriate end for students? Research and Teaching in Developmental Education, 24(1), 90-92.

Wolbers, A., Dostal, H. M., Graham, S., Cihak, D., Kilpatrick, J. R., \& Saulsburry, R. (2015). The writing performance of elementary students receiving strategic and interactive writing instruction. Journal of Deaf Studies and Deaf Education, 20(4), 385-398. https://doi.org/10.1093/deafed/env022

$\mathrm{Xu}$, D. (2016). Assistance or obstacle? The impact of different levels of English developmental education on underprepared students in community colleges. Educational Researcher, 45(9), 496-507. https://doi.org/10.3102/0013189X16683401

Zamel, V. (1992). Writing one's way into reading. TESOL Quarterly, 26, 463-485. https://doi.org/10.2307/3587174

Zamel, Z., \& Spack, R. (2006). Teaching multilingual learners across the curriculum: Beyond the ESOL classroom and back again. Journal of Basic Writing, 25(2), 126-152. https://doi.org/10.37514/JBW-J.2006.25.2.07

\section{Copyrights}

Copyright for this article is retained by the author(s), with first publication rights granted to the journal.

This is an open-access article distributed under the terms and conditions of the Creative Commons Attribution license (http://creativecommons.org/licenses/by/4.0/). 